\title{
Polyglycolic Acid Suture in Peripheral Nerve II: Sutured Sciatic Nerve
}

\author{
ALAN R. HUDSON AND DANIEL HUNTER
}

SUMMARY: This experiment investigates the holding property of polyglycolic acid suture in repair of divided dog sciatic nerves and the influence of absorption of this synthetic material on regeneration. The conclusion is that $P G A$ maintains its tensile strength sufficiently long to allow both physical union and good regeneration of the divided nerve. The suture absorption does not influence regeneration.

RÉSUMÉ: Cette expérience a pour but d'investiguer la propriété de résistance de la suture à l'acide polyglycolique dans la "réparation" des nerfs sciatiques sectionnés d'un chien et de l'influence de l'absorption de ce matériel synthétique sur la regénération. La conclusion est que le PGA maintient sa force d'extensibilité suffisamment longtemps pour permettre l'union physique de même qu'une bonne regénération du nerf sectionné. L'absorption de la suture $n$ influence pas la regénération.
From the Department of Neurosurgery, St. Michael's Hospital, University of Toronto.

Reprint request to Dr. Alan R. Hudson, Assistant Professor, Department of Neurosurgery, St. Michael's Hospital, 30 Bond Street, Toronto, Ontario, Canada. M5B IW8.
The fascicles of the proximal and distal stump of a severed nerve have to be held in apposition for a sufficient length of time to allow the regenerating axon clusters to gain the endoneurial environment of the distal stump and to allow reconstitution of the perineurium around these fibers so that the endoneurial environment within the fascicle is restored. Epineurial fibrosis occurs simultaneously and aids in the maintenance of physical union of the anastomosis. Once this has occurred the presence of the suture material is no longer necessary and may even be undesirable. Polyglycolic acid suture (PGA) has been found to cause minimal reaction when implanted in mammalian peripheral nerve (Hudson et al., 1975). The aim of this experiment was to ascertain whether or not PGA suture could maintain its tensile strength for a sufficient length of time to allow healing of a severed peripheral nerve and whether absorption of the suture would improve the final result. No report exists in the literature concerning the use of synthetic absorbable suture in peripheral nerve surgery.

\section{METHOD}

The sciatic nerves of 10 adult mongrel dogs were divided at mid thigh level under clean but not aseptic conditions. After the inter- and intrafascicular bleeding had ceased the nerves were sutured with 6-0 caliber material. Procedures were conducted under operating loupes. There were 6 to 8 epineurial sutures placed between proximal and distal stumps. In each animal one sciatic nerve was sutured with monofilament nylon and the other with multifilament PGA suture. No splints were applied and the dogs were allowed to wake up from the general anaesthetic and run around their cages. The animals were sacrificed at 7 through 91 days and biopsies were taken at the suture line and 2 centimeters distal to the suture line. These were fixed according to the method of Morris et al., (1972). Biopsies were embedded in Araldite and sectioned on an LKB 3 microtome. Transverse sections of the 20 nerves were examined by light microscopy and under a Philips 300 electron microscope.

\section{RESULTS}

The nerves were examined in situ and the occurrence of bulb formation, adherence to surrounding tissues and colour and caliber of distal stumps were recorded. The only difference seen between the nerves sutured with PGA and nylon was that the suture material was not visible in the former and was seen in the latter. The suture lines were smooth and not excessively bulbous. Light adhesions had formed between the suture line and the surrounding tissues and these were easily dissected free. No instance of suture line disruption occurred on either side. Infection was not recorded in any animal.

The changing microtopography of the terminal 2 millimeters of the proximal stump was identical to that described in the divided sciatic nerve of the rat in the 4 papers of Morris et al. (1972). The wave of traumatic degeneration is succeeded by intense regenerative activity with the formation of regenerative axon sprout clusters (Fig. 1). This sequence of events occurs regardless of whether or not the proximal stump is sutured to the distal stump. The find- 
ings in nerve sutured with PGA were identical to those of nerves sutured with nylon and also identical to a series of rat sciatic nerves sutured with 10-0 monofilament nylon (Hudson et al., 1970).

Transverse sections taken at the suture line of nerves sutured with PGA reveal that the fascicular pattern is scarcely visible. A single large fascicle is seen containing the regenerating axon clusters and the elements of the anastomotic scar (Fig. 4). As the regenerative clusters cross the anastomotic line they are surrounded by Schwann cells and fibroblasts so that each regenerating unit runs in its own little compartment (Fig. 5). The sutures occasionally penetrated immediately beneath the perineurium. The cellular reaction to the PGA suture material was identical to that described in the rat i.e. minimal, and blended with the cells involved in perineurial restoration. This reaction did not intrude into the fascicle (Figure 3). The extent of regenerative activity on one hand and fibroblast and collagen density on the other hand, was evaluated in the paired nerves. No difference was seen and the process of compartmentation was identical to that observed in the sutured rat sciatic nerve. Biopsies taken a few millimeters distal to the suture line show the restoration of the fascicular pattern of the distal stump and, in addition, groups of interfascicular regenerative units were seen. The intrafascicular regenerating axon clusters grow into the endoneurial tissues of the distal fascicles and initially lie between large cells. These large cells are Schwann cells undergoing Wallerian degeneration (Fig. 2).

Transverse sections of the distal stumps were examined 2 centimeters beyond the suture line. The normal fascicular pattern is noted and extrafascicular axons were not seen. Electron microscopic studies showed the sequential changes of Wallerian degeneration and subsequent reinnervation of the endoneurium. The regenerative axon clusters successively become less easily identifiable as the basement membrane surrounding each clus-

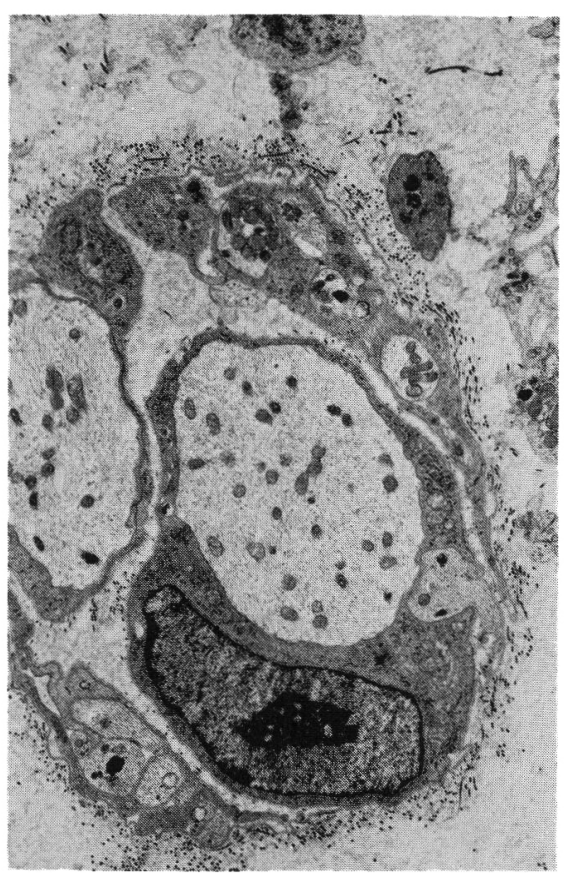

Figure I-PGA 9 days. Suture line. Regenerating axon sprouts. X6440.

ter breaks down, the axons enlarge in caliber and reduce in numbers and finally remyelinate (Figs. $6 \& 7$ ). The pattern of Wallerian degeneration is therefore slowly replaced by maturing axons although the occasional

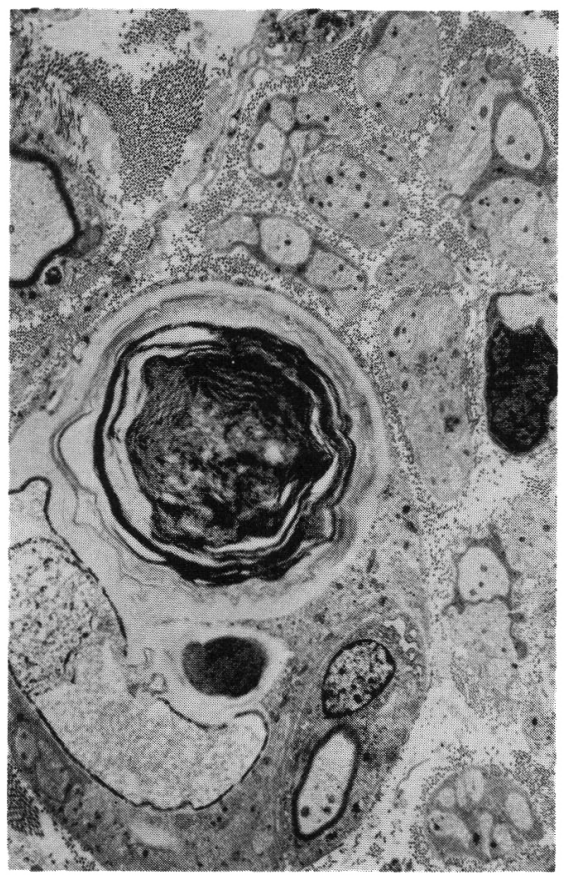

Figure 2-PGA 41 days. 2 centimeters distal. Regenerating axons growing past fiber undergoing Wallerian degeneration. X9520.

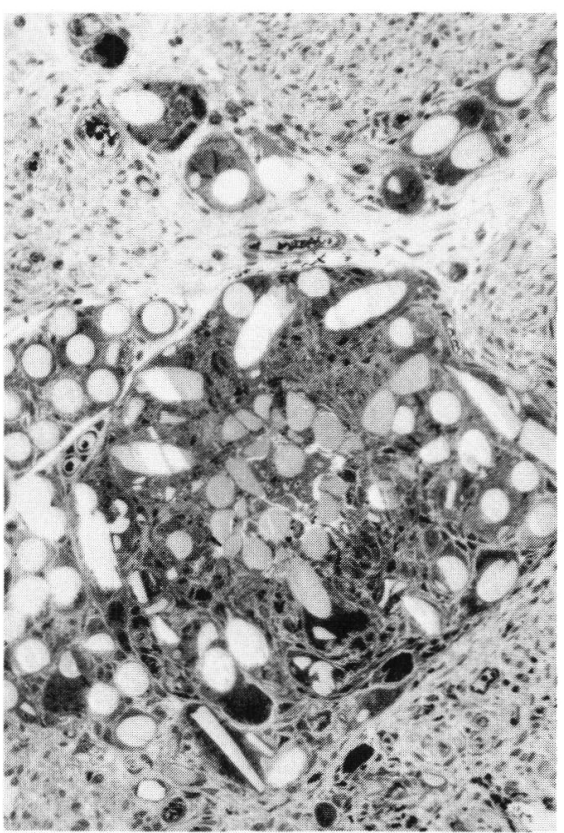

Figure 3-PGA 41 days. Knot of PGA in epineurium showing profiles of PGA suture filaments. (Light X200).

Schwann cell, packed with myelin debris, persists as late as the $91 \mathrm{st}$ day. Blind examination of the biopsies taken at this point in the 63,77 and 91 day animals showed excellent regeneration in every case and no

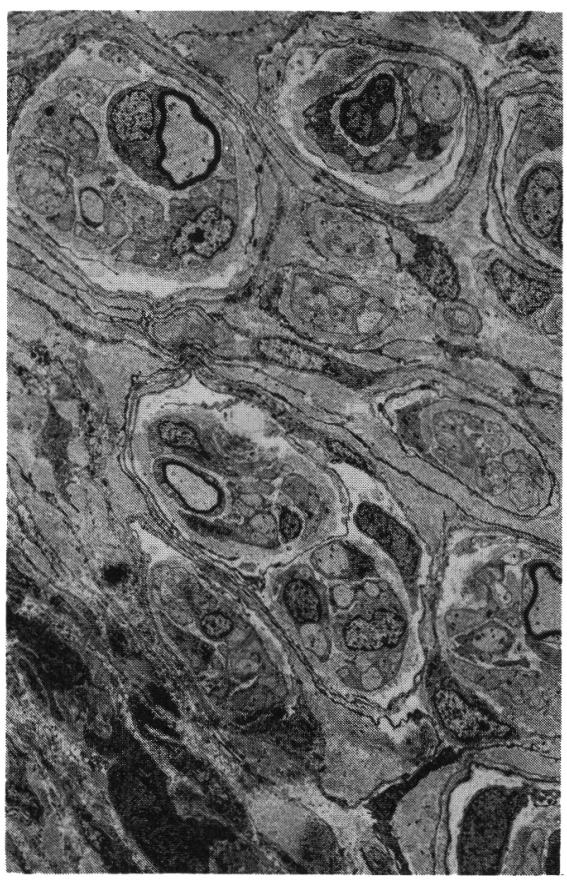

Figure 4-PGA 63 days. Suture line. Regenerating units surrounded by compartment walls of fibroblasts and Schwann cells. X2100. 


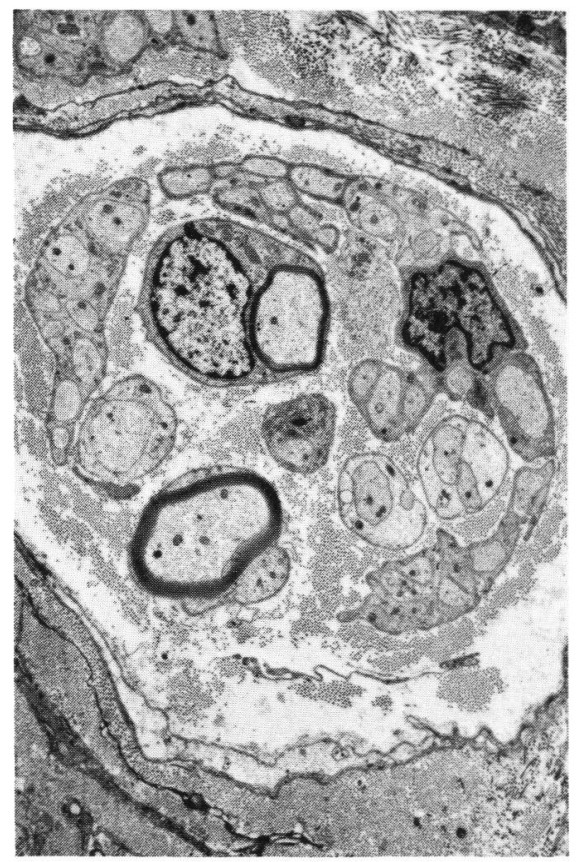

Figure 5-PGA 63 days. Suture line. Regenerating unit showing 2 myelinated axons. $\mathrm{X} 4480$.

difference in fiber density or caliber could be distinguished between those nerves sutured with PGA and nylon (Fig. 8).

In the epineurial tissues the initial cellular reaction to $\mathrm{PGA}$ and nylon

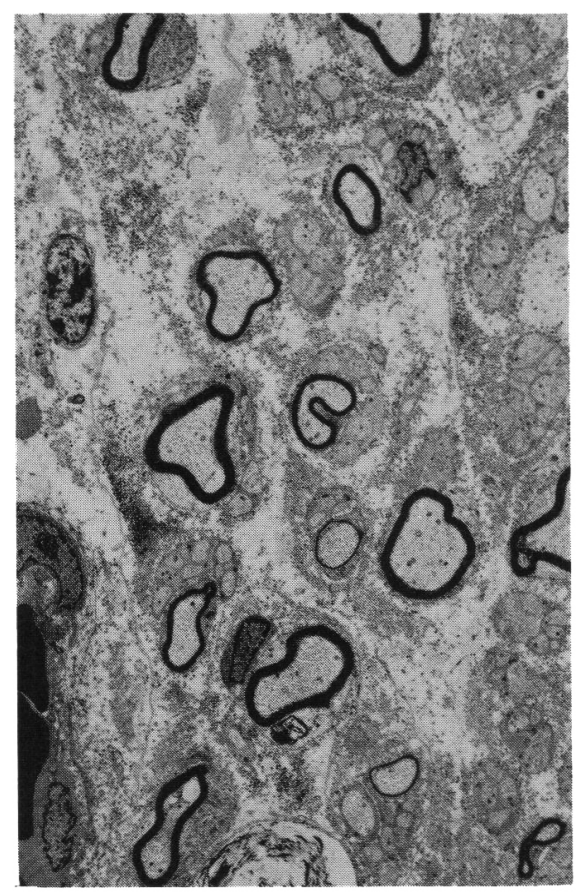

Figure 7-PGA 77 days. 2 centimeters distal. Excellent regeneration. Capillary left lower. Myelin remnants below center. X2500. was identical. The process of polyglycolic acid absorption appears to be identical to that described in the rat and small fragments of PGA were observed in an intracellular position in the 91 day animal (Fig. 9).

\section{DISCUSSION}

Experience with electron microscopic examination of sutured nerve and lesions in continuity in both animal and human examples leads us to conclude that the degree of fibroblast, Schwann cell and collagen proliferation at the suture line is related to 2 main factors. The first is the presence of hematoma and necrotic debris between divided fascicles. This occurs for example, when the proximal and distal stumps are insufficiently trimmed back in a secondary repair. The second factor is the accuracy and rapidity of restoration and maintenance of the integrity of the perineurial tubes. These two factors are independent of the suture itself. The intrusion of any suture material beneath the perineurium will incite scarring around that stitch. PGA excites minimal reaction in fascicles and is therefore an ideal suture in this regard. Bulb formation

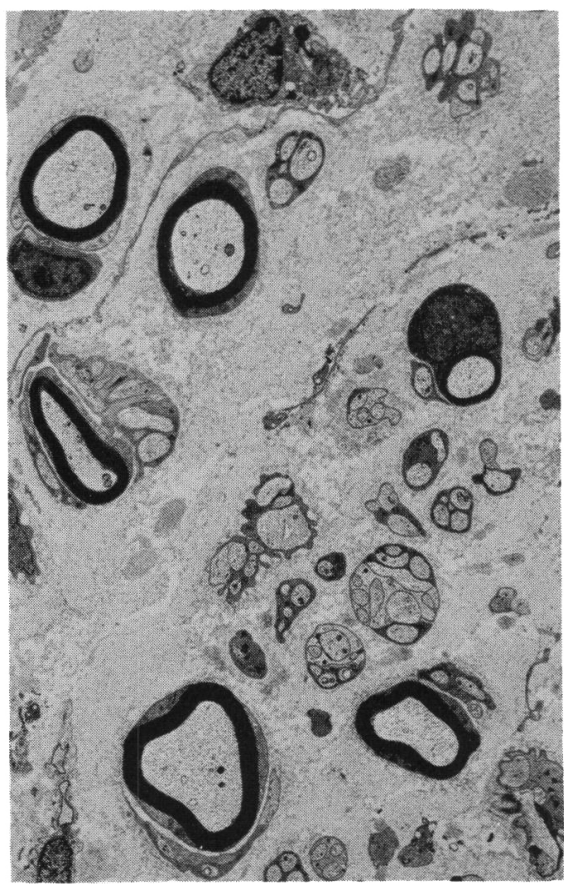

Figure 8-PGA 91 days. 2 centimeters distal. Normal appearance restored. $\times 2640$.

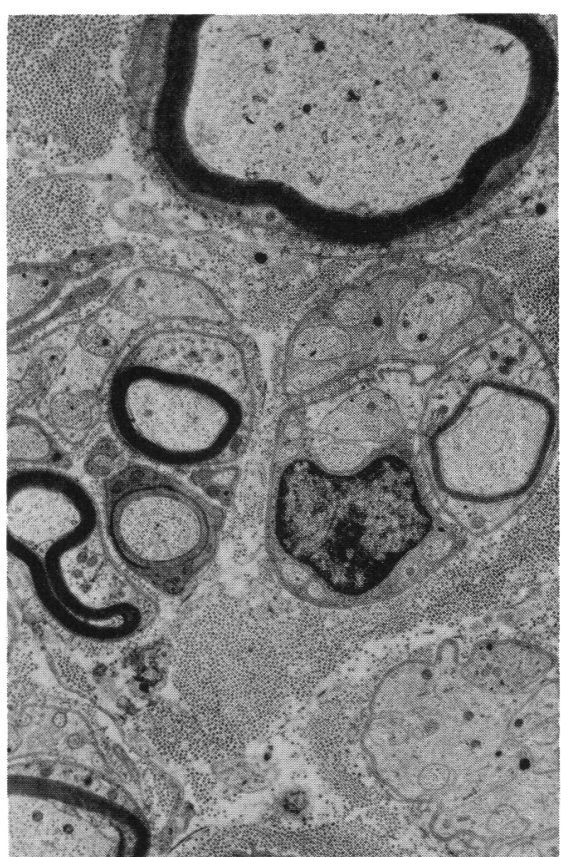

Figure 6-PGA 77 days. 2 millimeters distal to suture line. 2 regenerating units. The right hand unit contains a single myelinated fiber and the left 3 myelinated fibers, one of which is sectioned at a node of Ranvier. X6440.

at the suture line is directly related to the accuracy of perineurial apposition at the time of suture and is not

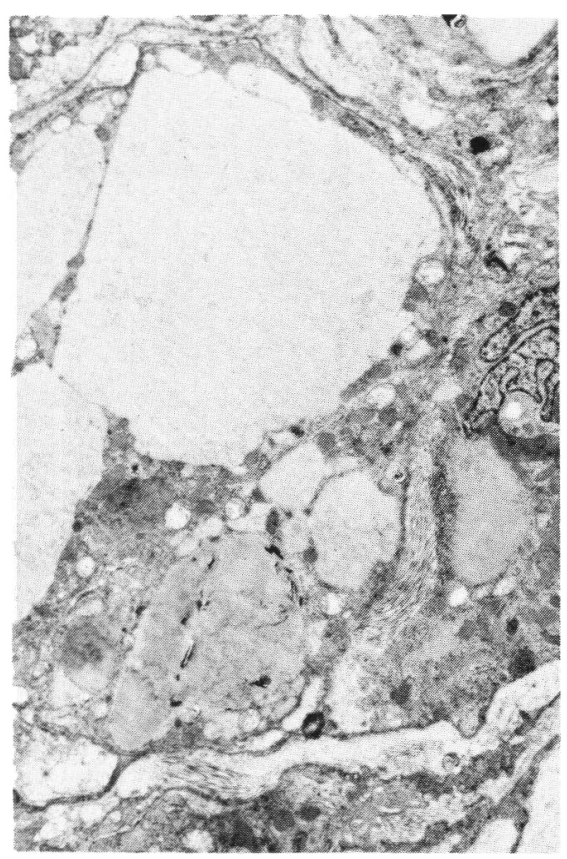

Figure 9-PGA 91 days. Suture line. Intracellular PGA fragments (above) in epineurial macrophage. X2000. 
dependent on the use of either PGA or nylon suture. If large quantities of regenerating axons escape at the suture line, either because of inaccurate fascicular orientation or because of partial disruption of the suture line, a larbe bulb will form. PGA itself does not excite an excessive inflammatory response and thus does not contribute to the formation of any bulb in continuity. We conclude that bulb formation and anastomotic scarring are related to surgical technique rather than the choice of suture material. PGA is easily handled, once experience is gained at tying knots with this material, and there are no contraindications to the use of this material with regard to practical ease of handling in the operating room.

The real test as to the efficiency of the anastomosis is the transmission of regenerative axon sprouts distal to the suture line. Kline (1975) has repeatedly stressed that this regenerative transmission cannot be gauged by observation or palpation of the suture line in the experimental or clinical setting, and can only be measured by evoking nerve action potentials or histological examina- tion of the nerve distal to the suture line. In every instance regeneration was excellent and no difference could be discerned in those nerves sutured with PGA and nylon suture. We therefore conclude that PGA suture maintains its tensile strength for a sufficient length of time to allow both physical union and regeneration of sciatic nerve under the circumstances of this experiment. The suture lines were submitted to a fair degree of stretch as none of the animals was splinted. We conclude that PGA is at least as good as nylon for the suture of mammalian peripheral nerve. (Both sutures caused extremely little reaction.) No particular benefit was derived from the fact that the suture material was absorbed. It is suggested that this particular aspect will be of great importance in multifascicular suturing as experiments with this technique indicate that the suture material is incorporated within the nerve as a whole and thus occupies an intrafascicular position. An absorbable suture may well be beneficial in this situation and we propose to investigate this hypothesis in a further experiment.

\section{ACKNOWLEDGEMENTS}

Equipment supplied by MRC Grant No. MA3993. PGA suture (Dexon) supplied by Davis and Geck.

\section{REFERENCES}

HUDSON, A. R., BILBAO, J. M. and HUNTER, D. (1975). Polyglycolic Acid Suture in Peripheral Nerve: An electron microscopic study. Canad. J. Neurol. Sciences. Vol. 2, 1, 17-21.

HUDSON, A. R., MORRIS, J. and WED. DELL, G. (1960). An electron microscopic study of regeneration in sutured rat sciatic nerves. Surg. Forum, 21, 451-453.

MORRIS, J. H., HUDSON, A. R. and WEDDELL, G. (1972). The traumatic degeneration of myelin in the proximal stump of the divided nerve. $Z$. Zellforsch. 124, 76-102.

MORRIS, J. H., HUDSON, A. R, and WEDDELL, G. (1972). The development of the "Regenerating Unit". Z. Zellforsch. 124, 103-130.

MORRIS, J. H., HU.DSON, A. R., and WEDDELL, G. (1972). Changes in the axons of the proximal stump. Z. Zellforsch, 124, 131-164.

MORRIS, J. H., HUDSON, A. R. and WEDDELL, G. (1972). Changes in fascicular microtopography, perineurium and endoneurial fibroblasts. Z. Zellforsch. 124, 165-203.

KLINE, D. G., HUDSON, A. R. HACKETT, E. R. and BRATTON, B. R. (1975). Progression of partial experimental injury to peripheral nerve. J. Neurosurg. $42,1-22$. 